\title{
Antioxidant Activities of Selective Gluten Free Ancient Grains
}

\author{
George E. Inglett, Diejun Chen, Sean X. Liu \\ Functional Foods Research Unit, National Center for Agricultural Utilization Research, Agricultural Research \\ Service, United States Department of Agriculture, Peoria, IL, USA \\ Email: George.Inglett@ars.usda.gov
}

Received 27 March 2015; accepted 4 May 2015; published 5 May 2015

Copyright @ 2015 by authors and Scientific Research Publishing Inc.

This work is licensed under the Creative Commons Attribution International License (CC BY).

http://creativecommons.org/licenses/by/4.0/

c) (i) Open Access

\section{Abstract}

Ancient grains were known for special nutritional values along with gluten free qualities. Amaranth, quinoa, teff, and buckwheat flours were evaluated for pasting properties, water holding capacities, phenolic contents, and antioxidant activities (free and bound). They all had higher water holding capacities than wheat flour. Amaranth, quinoa, and teff showed higher pasting viscosities than wheat flour. Buckwheat flour had the highest free, bound and total phenolic contents among the flours in all aqueous extracts. The bound phenolic contents were higher than the free phenolic contents regardless of the solvents with the exception of water extraction of quinoa and buckwheat. The free phenolic compounds for all four flours were highest in water extract, and least in $100 \%$ ethanol. Bound antioxidant activities were much higher than the free antioxidant activities regardless of solvents for all products. The free antioxidant activities from water and $50 \%$ ethanol were higher than $100 \%$ ethanol. In contrast, more bound phenolics were extracted with $100 \%$ ethanol than water and $50 \%$ ethanol. Our study suggested that the total phenolic contents and antioxidant activities of grains could be underestimated in the literature without considering the bound phenolic compounds. These ancient grains have nutrition, antioxidants, and textural qualities suitable for functional foods.

\section{Keywords}

Amaranth, Quinoa, Teff, Buckwheat, Gluten-Free, Antioxidant, Pasting

\section{Introduction}

Amaranth, quinoa, teff and buckwheat have received considerable interest because of their gluten-free uniqueness. Gluten is found in grains such as wheat, barley and rye. Gluten causes inflammation in the small intestines 
of people with celiac disease. A gluten-free diet helps people with celiac disease control their signs and symptoms and prevent complications [1].

Amaranth (Amaranthus caudatus), an ancient grain, contains about thirty percent more protein than cereals such as rice, sorghum and rye [2]. Amaranth is a source of thiamine, niacin, riboflavin, folate, and dietary minerals including calcium, iron, magnesium, phosphorus, zinc, and manganese that are comparable to grain products such as wheat germ, oats, and others [3]. Amaranth flour particularly has an unusually rich source of the essential amino acid, lysine, which is low in other grains [4]. Regular consumption of amaranth oil reduces blood pressure and cholesterol levels while improving antioxidant status and some immune parameters because amaranth seed oil may be benefit for those with hypertension and cardiovascular disease [5].

Quinoa (Chenopodium quinoa) is a pseudocereal or pseudograin rather than a cereal or grain that has been called a superfood because of its remarkable nutritional value. Quinoa seeds contain large amounts of vitamins; protein $(13 \%-14 \%)$ with a good digestibility; a balanced amino acid with high lysine and methionine; and a good source of dietary fiber, K, Ca, Mg, P, and Fe that are much higher than conventional cereals [6] [7]. Quinoa contains antioxidant phytonutrients (polyphenols and phytosterols) and flavonoids (quercetin and kaempferol) in concentrated amounts with possible nutraceutical benefits [7] [8]. Also, quinoa can be considered as an oil crop containing omega-6 with notable vitamin E content. Moreover, quinoa starch has useful physicochemical properties, such as viscosity and freeze stability [8].

Another ancient crop, teff (Eragrostis tef), also has an attractive nutrition profile, being high in dietary fiber with significant levels of the minerals phosphorus, magnesium, aluminum, iron, copper, zinc, boron and barium, and thiamin [3]. Teff is high in proteins with an excellent amino acid composition including all 8 essential amino acids for humans. It is also higher in lysine than wheat or barley along with its high carbohydrates and fiber contents [9].

Buckwheat (Fagopyrum esculentum Moench), a well known pseudocereal, possesses good sources of manganese, magnesium and dietary fiber as well as its gluten free quality. Many of the health benefits of buckwheat have been attributed to its high levels of phenolic compounds and antioxidant activity [10]. Whole buckwheat contains 2 - 5 times more phenolic compounds than oats or barley, while buckwheat bran and hulls have 2 - 7 times higher antioxidant activity than barley, triticale, and oats [11] [12]. The primary antioxidants in buckwheat are rutin, quercetin, hyperin, and catechins [13].

Recently, amaranth, quinoa, buckwheat, and teff flour have been used in food products to replace wheat flour. The different levels of amaranth flour also have been mixed with the wheat flour and baking ingredients that were fermented, molded, pan-proved and baked. The loaf volume decreased with increasing amounts of amaranth grain flour. There were significant differences in using 15\% amaranth flour in sensory evaluation [14]. Quinoa flour can substitute or completely replace wheat flour in many recipes. Studies on food products containing quinoa flour, such as noodles, cookies, and breads, have been reported [15]. Buckwheat flour was used for many food products, such as gluten-free bread using tartary buckwheat and chia flour rich in flavonoids and omega-3 fatty acids as ingredients [16]. The wheat flour bread containing $22.5 \%$ to $45 \%$ blends of teff, green pea and buckwheat (BW) flours provided superior nutritional composition with acceptable sensory properties compared with the $100 \%$ wheat flour bread [17].

Antioxidant-rich diets have been associated with a lower incidence of cardiovascular disease, cancers, and age-related degenerative processes [18]. Determination of total antioxidant activity including bound and free compounds provided a tool for investigating the protective role of antioxidant-rich products in degenerative diseases and potentially positive health benefits [19] [20]. A direct method was developed for total antioxidant activities by mixing solid samples with free radicals followed by a subsequent spectrometric measurement that gave total antioxidant activities higher than those by the traditional procedures [21].

The objective of this research was to compare the nutrition of amaranth, quinoa, teff and buckwheat, and study their physical and chemical properties including water holding capacity, pasting properties, phenolic content, and antioxidant activities. This study will provide information for developing new functional gluten free products for health concerned consumers.

\section{Materials and Methods}

\subsection{The Source of Ingredients}

Buckwheat flour (Farinetta) were supplied by Minn-Dak Growers Ltd. (Grand Forks, ND). Organic Gluten free 
amaranth flour certified by international certification services Inc. was purchased from Dakota Prairie Organic Flour Co. Harvey, ND, USA. Gluten free quinoa and teff flour was purchased from Bob’s Red Mill, Milwaukie, OR, USA.

\subsection{Water-Holding Capacity}

The water-holding capacity (WHC) of the samples was determined according to a previous procedure with minor modifications [22]. Each sample (2 g, dry weight) was mixed with $25 \mathrm{~g}$ of distilled water and vigorously mixed for 1 min to a homogenous suspension using a Vortex stirrer, held for $2 \mathrm{~h}$, and centrifuged at $1590 \mathrm{~g}$ for 10 min. Each treatment was replicated twice. Water-holding capacity was calculated on dry basis by the difference between the weight of water added and decanted.

\subsection{Pasting Property Measurement}

The pasting properties of samples were evaluated using a Rapid Visco Analyzer (RVA-4, Perten Scientific, Springfield, IL). Samples (2.24 g, dry basis) were made up to a total weight of $28 \mathrm{~g}$ with distilled water in a RVA canister ( $8 \%$ solids, w/w). The viscosity of the suspensions was monitored during the following heating and cooling stages. Suspensions were equilibrated at $50^{\circ} \mathrm{C}$ for $1 \mathrm{~min}$, heated to $95^{\circ} \mathrm{C}$ at a rate of $6.0^{\circ} \mathrm{C} / \mathrm{min}$, maintained at $95^{\circ} \mathrm{C}$ for $5 \mathrm{~min}$, and cooled to $50^{\circ} \mathrm{C}$ at rate of $6.0^{\circ} \mathrm{C} / \mathrm{min}$, and held at $50^{\circ} \mathrm{C}$ for $2 \mathrm{~min}$. For all test measurements, a constant paddle rotating speed $(160 \mathrm{rpm})$ was used throughout the entire analysis except for $920 \mathrm{rpm}$ in the first $10 \mathrm{~s}$ to disperse sample. Each sample was analyzed in duplicate. The results were expressed in Rapid Visco Analyser units (RVU, 1 RVU = 12 centipoises).

\subsection{Sequential Alkaline Extraction}

Step 1: double extraction for free compounds.

The extraction conditions were modified based on the research by Serpen (2008) [21]. Samples (1 g) were extracted with $10 \mathrm{ml}$ of $50 \%$ ethanol twice under $\mathrm{N}_{2}$ by shaking in a water bath for 20 min. Each extraction step was followed by centrifugation at $3000 \mathrm{rpm}$ (1462 g) for $10 \mathrm{~min}$. Combined supernatants were used for free phenolic and antioxidant activity measurements.

Step 2: alkaline extraction for bound compounds.

The solid residue from double extraction was hydrolyzed with $20 \mathrm{~mL}$ of $2 \mathrm{~N}$ sodium hydroxide for $2 \mathrm{~h}$ under $\mathrm{N}_{2}$ by shaking in the dark at room temperature [23]. The alkaline extracts were acidified using about $20 \mathrm{~mL}$ of 2 $N \mathrm{HCl}$ and centrifuged at $3000 \mathrm{rpm}$ (1462 g) for $10 \mathrm{~min}$. The supernatants were used for bound phenolic and antioxidant activity measurements.

\subsection{Total Phenolic Content}

Phenolic content was determined by the Folin-Ciocalteau colourimetric method with minor modifications [24] [25]. To $100 \mu \mathrm{L}$ of extract, $7.9 \mathrm{~mL}$ of deionized water and $0.5 \mathrm{~mL}$ of Folin-Ciocalteau reagent (F9252, Sigma Aldrich, St Louis, MO) were added, mixed on a vortex mixer, and $1.5 \mathrm{~mL}$ of $1.85 \mathrm{M} \mathrm{Na}_{2} \mathrm{CO}_{3}$ was added after 15 min. Absorbance of samples was measured at $765 \mathrm{~nm}$ after $2 \mathrm{~h}$. Gallic acid was used as a standard and results were expressed as mg of gallic acid equivalents per g (d.m.).

\subsection{Antioxidant Activity}

Antioxidant activity determination was modified using a previous method by reacting $0.5 \mathrm{~mL}$ of extract with 0.5 $\mathrm{mL}$ of $200 \mu \mathrm{M}$ 2, 2-diphenyl-1-picryl-hydrazyl (DPPH) in a cuvette for 40 minutes in dark [26]. Convert the cuvettes after adding reagent and prior to reading the absorbance at $515 \mathrm{~nm}$. Results were expressed as 6-hydroxy-2, 5, 7, 8-tetramethylchroman-2-carboxylic acid (Trolox) equivalents per g (d.m.).

\subsection{Statistical Analysis}

Data from replicated samples were analyzed using SAS software using analysis of variance with Duncan’s multiple comparison adjustment to determine significant differences $(p<0.05)$ between treatments [27]. 


\section{Results and Discussion}

\subsection{Nutrition Composition}

The ancient gain flours in Table 1 contain more proteins and minerals including calcium, iron, magnesium, phosphorus, potassium, and zinc than wheat flour. Amaranth contains the highest magnesium and phosphorus;

Table 1. Composition of ancient grains and wheat.

\begin{tabular}{|c|c|c|c|c|c|c|}
\hline Proximates (per 100 g) & Unit & Amaranth & Quinoa & Teff & Buckwheat & Wheat \\
\hline Water & g & 11.29 & 13.28 & 8.82 & 9.75 & 10.74 \\
\hline Energy & kcal & 371 & 368 & 367 & 343 & 340 \\
\hline Protein & g & 13.56 & 14.12 & 13.3 & 13.25 & 13.21 \\
\hline Total lipid (fat) & g & 7.02 & 6.07 & 2.38 & 3.4 & 2.50 \\
\hline Carbohydrate, by difference & g & 65.25 & 64.16 & 73.13 & 71.5 & 71.97 \\
\hline Fiber, total dietary & g & 6.7 & 7 & 8 & 10 & 10.7 \\
\hline Sugars, total & g & 1.69 & $-{ }^{*}$ & 1.84 & - & 0.41 \\
\hline \multicolumn{7}{|l|}{ Minerals } \\
\hline Calcium, Ca & $\mathrm{mg}$ & 159 & 47 & 180 & 18 & 34 \\
\hline Iron, Fe & $\mathrm{mg}$ & 7.61 & 4.57 & 7.63 & 2.2 & 3.6 \\
\hline Magnesium, Mg & $\mathrm{mg}$ & 248 & 197 & 184 & 231 & 137 \\
\hline Phosphorus, P & $\mathrm{mg}$ & 557 & 457 & 429 & 347 & 357 \\
\hline Potassium, K & $\mathrm{mg}$ & 508 & 563 & 427 & 460 & 363 \\
\hline Sodium, $\mathrm{Na}$ & $\mathrm{mg}$ & 4 & 5 & 12 & 1 & 2 \\
\hline Zinc, Zn & $\mathrm{mg}$ & 2.87 & 3.1 & 3.63 & 2.4 & 2.6 \\
\hline \multicolumn{7}{|l|}{ Vitamins } \\
\hline Vitamin C, total ascorbic acid & $\mathrm{mg}$ & 4.2 & - & - & - & - \\
\hline Thiamin (B1) & $\mathrm{mg}$ & 0.116 & 0.36 & 0.39 & 0.101 & 0.502 \\
\hline Riboflavin & $\mathrm{mg}$ & 0.2 & 0.318 & 0.27 & 0.425 & 0.165 \\
\hline Niacin & $\mathrm{mg}$ & 0.923 & 1.52 & 3.363 & 7.02 & 4.957 \\
\hline Vitamin B-6 & $\mathrm{mg}$ & 0.591 & 0.487 & 0.482 & 0.21 & 0.407 \\
\hline Folate, DFE & $\hat{A} \mu g$ & 82 & 184 & - & 30 & 44 \\
\hline Vitamin B-12 & $\hat{A} \mu g$ & - & - & - & - & - \\
\hline Vitamin A, RAE & $\hat{A} \mu g$ & - & 1 & - & - & - \\
\hline Vitamin A, IU & IU & 2 & 14 & 9 & - & 9 \\
\hline Vitamin E (alpha-tocopherol) & $\mathrm{mg}$ & 1.19 & 2.44 & 0.08 & - & 0.71 \\
\hline Vitamin D (D2 + D3) & $\hat{A} \mu g$ & - & - & - & - & - \\
\hline Vitamin D & IU & - & - & - & - & - \\
\hline Vitamin K (phylloquinone) & $\hat{\mathrm{A}} \mu \mathrm{g}$ & - & - & 1.9 & - & - \\
\hline \multicolumn{7}{|l|}{ Lipids } \\
\hline Fatty acids, total saturated & g & 1.459 & 0.706 & 0.449 & 0.741 & 0.43 \\
\hline Fatty acids, total monounsaturated & g & 1.685 & 1.613 & 0.589 & 1.04 & 0.283 \\
\hline Fatty acids, total polyunsaturated & g & 2.778 & 3.292 & 1.071 & 1.039 & 1.167 \\
\hline Cholesterol & $\mathrm{g}$ & - & - & - & - & - \\
\hline
\end{tabular}

*Under detection limit. 
quinoa has the highest potassium; and teff has the highest calcium, iron, and zinc of all products. Also they are all rich in vitamins. Amaranth has the highest vitamin C, and vitamin B-6, quinoa has highest folate, vitamin E and D; buckwheat has highest riboflavin and niacin contents. Quinoa and teff contain higher thiamin (B1) than the other two ancient grain flours. Vitamin B1 helps the body metabolizes fats and protein, and is required for healthy skin, hair, eyes, and liver. It also helps the nervous system function properly and good brain functions [28]. Particularly, teff is the only one containing Vitamin $\mathrm{K}$ among the products in the Table 1 . Vitamin $\mathrm{K}$ is a fat-soluble vitamin that the body stores it in fat tissue and the liver. It is best known for its role in helping blood clot and bone health [28]. Both quinoa and teff have high quality lipids including monounsaturated and polyunsaturated fatty acid contents. These ancient grains have endured the ages from early civilizations as an important food source to its current resurgence as a highly nutritious gluten-free source. Therefore, the nutritional value of gluten free baked products could be improved by adding ancient grain products to recipes.

\subsection{Water-Holding Capacity}

The WHC of the ancient grains and wheat flours are shown in Figure 1. Among the four gluten free flours, buckwheat had the highest WHC (164\%), the teff ranked in second (144\%), and WHC of amaranth was the least (125\%), that was slightly lower than WHC of quinoa (130\%). Overall, all ancient grain flours in this study had higher WHC than that of wheat flour (92\%). These gluten free ancient gain flours could be widely used in different food applications because of better WHC for improved texture along with nutrition compared to wheat flour.

\subsection{RVA Pasting Properties}

The pasting curves of all products were obtained by RVA expressed as RVU ( $1 \mathrm{RVU}=12$ centipoises). As shown in Figure 2, the pasting curves for all samples had dissimilar patterns. The Amaranth pasting viscosity exhibited a significantly high ( $\sim 52 \mathrm{RVU}$ ) and sharp viscosity peak ( 5 RVU/min) during the initial $11 \mathrm{~min}$

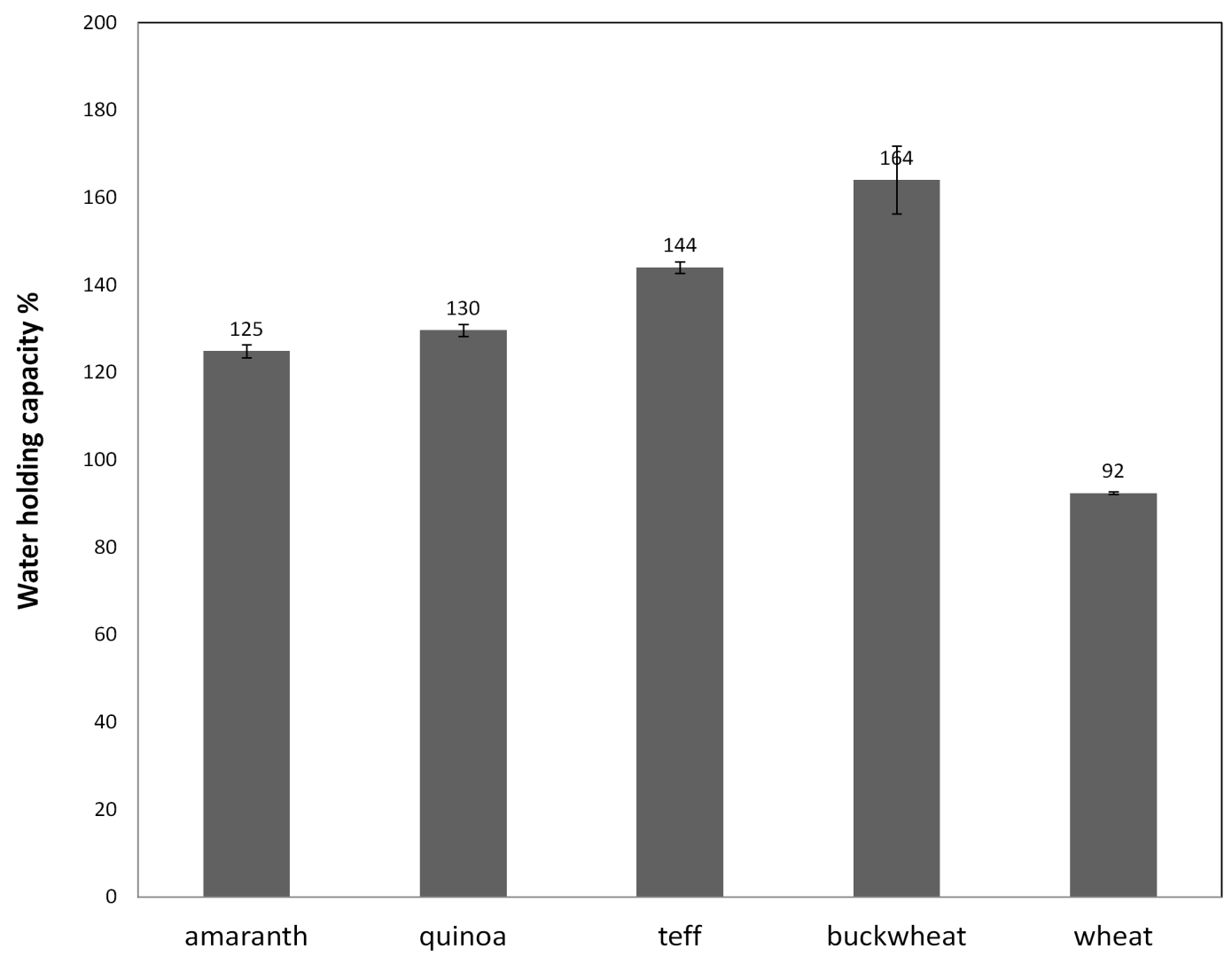

Figure 1. Water holding capacities ancient grain and wheat flours. 


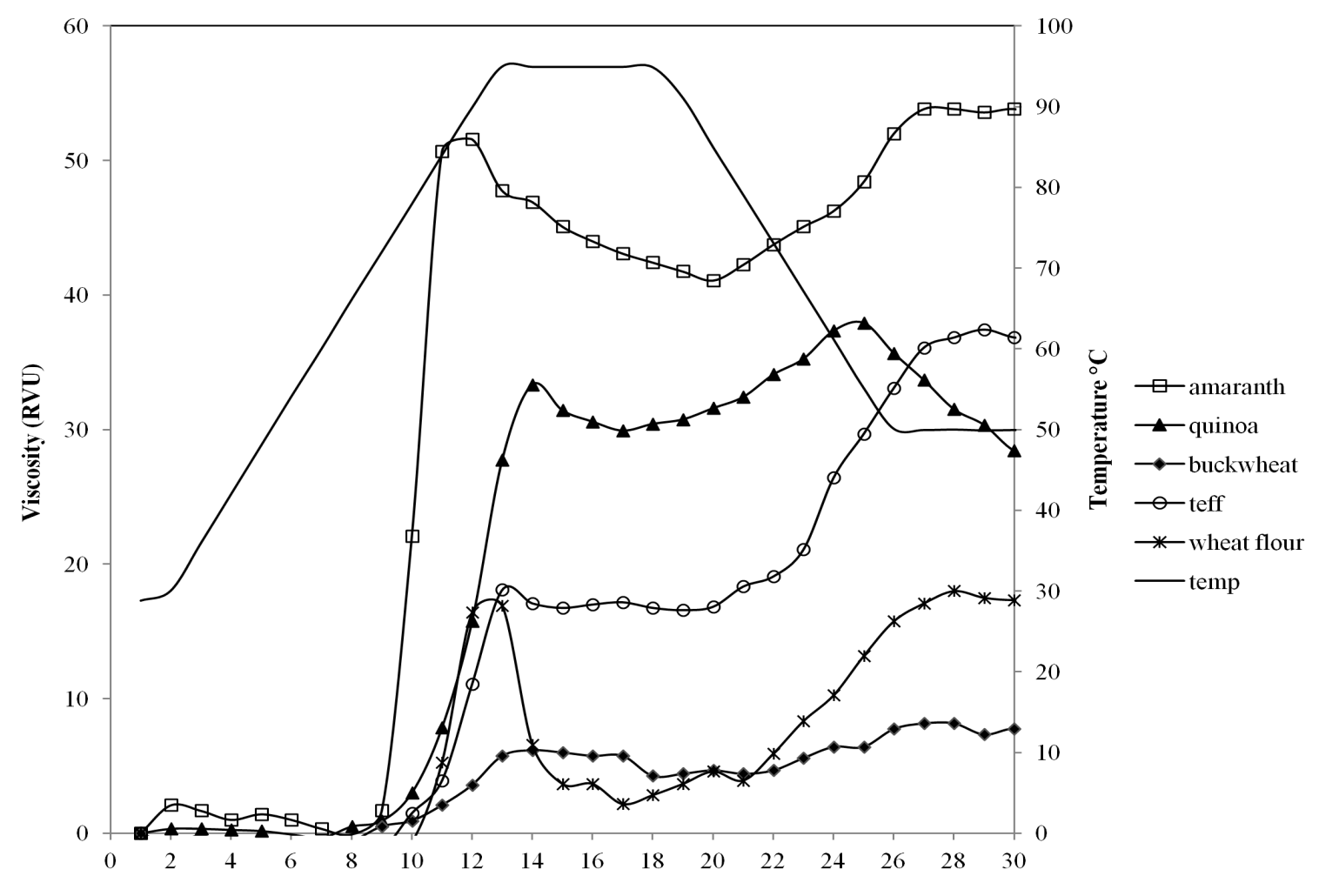

Time (min)

Figure 2. Pasting curves of ancient grain and wheat flours.

heating period at $\sim 90^{\circ} \mathrm{C}$ followed by a gradually decrease in viscosity (1 RVU/min) to $\sim 41 \mathrm{RVU}$ during continued heating and cooling at $18 \mathrm{~min}$, and increase to the final viscosity (53 RVU) during cooling down showing a break down (peak viscosity minus the lowest point of viscosity after peak). The viscosity of quinoa showed the initial peak ( $\sim 33 \mathrm{RVU})$ at $95^{\circ} \mathrm{C}$, and then the viscosity showed a shallow break down and then decreased to a final viscosity ( $28 \mathrm{RVU})$ that was lower than that of amaranth ( $\sim 53 \mathrm{RVU})$. The viscosity of teff increased to the initial peak ( $\sim 18 \mathrm{RVU})$ after temperature reaching $95^{\circ} \mathrm{C}$ at $12 \mathrm{~min}$, keeping a near constant viscosity during heating, and then increased sharply ( $2 \mathrm{RVU} / \mathrm{min}$ ) during cooling resulting in a final viscosity (37 RVU) that was higher than the final viscosity of quinoa ( $28 \mathrm{RVU}$ ). Perhaps, it was due to highest calcium content that reacted with protein in teff. It could be a similar mechanism to make tofu by coagulating proteins in soymilk with calcium or magnesium sulfate. The proteins coagulate when bonding occurs between the positively charged calcium ions and negatively charged anionic groups of the protein molecules. The calcium and magnesium in teff could be reacted with protein causing the increased viscosity during cooling.

Buckwheat flour had the lowest initial viscosity peak ( $\sim 6 \mathrm{RVU})$ than other samples at $95^{\circ} \mathrm{C}$, and then kept nearly constant value to the final viscosity ( $\sim 7 \mathrm{RVU})$ that was lowest among all samples. The initial peak ( 17 RVU) for wheat was similar to teff but it decreased sharply on $12 \mathrm{~min}$ at $95^{\circ} \mathrm{C}$. It is known that the viscosity of a completely gelatinized starch slurry decreases during heating [29].

The RVA data could provide useful information for food processing and product development. The product with low viscosity may be suitable for products such as cookies, muffin, or nutritional bars. The product with high viscosities could be used for products such as breads for improved the texture quality and health benefits.

\subsection{Free, Bound and Total Phenolic Contents}

Buckwheat flour had the highest free, bound and total phenolic contents among the four flours when extracted with water, 50\% ethanol and 100\% ethanol (Table 2). Buckwheat (Farinetta) flour contains a considerable amount of aleurone layer along with embryo. Cereals are rich in substituted cinnamic acids such as ferulic acid that are 
Table 2. Free, bound and total phenolic contents of ancient grain products in aqueous extracts using water, 50\% ethanol, and $100 \%$ ethanol.

\begin{tabular}{ccccccc}
\hline Samples & Ethanol (\%) & Free $\mathbf{~ m g / g}$ & \% of total & Bound $\mathbf{~ m g / g}$ & \% of total & Total mg/g \\
\hline Amaranth & 0 & $1.76 \pm 0.09 \mathrm{e}$ & 38.10 & $2.86 \pm 0.22 \mathrm{e}$ & 61.90 & $4.62 \pm 0.03 \mathrm{~d}$ \\
Amaranth & 50 & $0.6 \pm 0.01 \mathrm{~g}$ & 14.22 & $3.62 \pm 0.13 \mathrm{~d}$ & 85.78 & $4.22 \pm 0.14 \mathrm{ef}$ \\
Amaranth & 100 & $0.53 \pm 0.01 \mathrm{~g}$ & 11.91 & $3.92 \pm 0.13 \mathrm{~d}$ & 88.09 & $4.45 \pm 0.14 \mathrm{de}$ \\
Quinoa & 0 & $3.03 \pm 0.16 \mathrm{~d}$ & 77.30 & $0.89 \pm 0.07 \mathrm{~h}$ & 22.70 & $3.92 \pm 0.13 \mathrm{fg}$ \\
Quinoa & 50 & $1.65 \pm 0.02 \mathrm{e}$ & 44.72 & $2.04 \pm 0.10 \mathrm{~g}$ & 55.28 & $3.69 \pm 0.12 \mathrm{~g}$ \\
Quinoa & 100 & $0.88 \pm 0.06 \mathrm{f}$ & 22.51 & $3.03 \pm 0.11 \mathrm{e}$ & 77.49 & $3.91 \pm 0.05 \mathrm{fg}$ \\
Teff & 0 & $1.82 \pm 0.07 \mathrm{e}$ & 48.66 & $1.92 \pm 0.10 \mathrm{~g}$ & 51.34 & $3.74 \pm 0.17 \mathrm{~g}$ \\
Teff & 50 & $1.74 \pm 0.03 \mathrm{e}$ & 41.93 & $2.41 \pm 0.15 \mathrm{f}$ & 58.07 & $4.15 \pm 0.17 \mathrm{ef}$ \\
Teff & 100 & $0.96 \pm 0.09 \mathrm{f}$ & 20.38 & $3.75 \pm 0.12 \mathrm{~d}$ & 79.62 & $4.71 \pm 0.06 \mathrm{~d}$ \\
Buckwheat & 0 & $9.44 \pm 0.25 \mathrm{a}$ & 60.05 & $6.28 \pm 0.30 \mathrm{c}$ & 39.95 & $15.72 \pm 0.27 \mathrm{c}$ \\
Buckwheat & 50 & $7.20 \pm 0.25 \mathrm{~b}$ & 40.47 & $10.59 \pm 0.40 \mathrm{~b}$ & 59.53 & $17.79 \pm 0.17 \mathrm{a}$ \\
\hline Buckwheat & 100 & $3.78 \pm 0.04 \mathrm{c}$ & 22.03 & $13.38 \pm 0.24 \mathrm{a}$ & 77.97 & $17.16 \pm 0.22 \mathrm{~b}$ \\
\hline
\end{tabular}

esterified to cell walls, to arabinoxylan and arabinogalactan in the aleurone layer, and pericarp [30]. The free phenolic contents were $\sim 20 \%-60 \%$ of total phenolic contents while the bound phenolic contents were $22 \%$ - $79 \%$ of total phenolic contents. Overall, the bound phenolic contents were higher than free phenolic contents regardless of the ethanol concentrations with exception of water extraction of quinoa and buckwheat. Studies have reported that the phenolic compounds are primarily bound to cell walls for most cereal grains [23]. The bound phenolic compounds probably are released under alkaline extraction conditions. Amaranth, quinoa, and teff flour were all significantly lower in the free, bound, and total phenolic contents than that of buckwheat regardless of the ethanol concentrations.

Interestingly, the free phenolic compounds for all four products were significant highest in water extract, secondly in 50\% ethanol, and were least in (the) $100 \%$ ethanol. Cinnamic and benzoic acid derivatives are generally water soluble and universally present in plant foods [31]. It may be the explanation for the more free phenolic compounds when water or $50 \%$ ethanol was used for all four flours, respectively (Table 2). In contrast to the free phenolic contents, more bound phenolics were extracted with $100 \%$ ethanol than water and $50 \%$ ethanol. It implied that bound phenolics are more soluble in $100 \%$ ethanol.

The different letters indicated the significances between treatments in column $(p<0.05)$.

\subsection{Free, Bound and Total Antioxidant Activities}

The similar trends were observed for antioxidant activities as phenolic contents (Table 3). In general, the bound antioxidant activities are all much higher statistically than the free antioxidant activities for all products as phenolic content in spite of solvents. However, the differences of antioxidant activities bound among products seem not as large as bound phenolic contents. The free antioxidant activities ranged from $1.3 \%$ to $33.55 \%$ of total antioxidant activities whereas the bound antioxidant activities were ranged from $67.40 \%$ to $98.7 \%$ of total antioxidant activities. Our study suggests that the total phenolic contents and antioxidant activities of grains could be underestimated in the literature if not including the bound phenolic compounds.

The free antioxidant activities from water and 50\% ethanol were higher than those from absolute alcohol. The free antioxidant activities from water were higher than those from $50 \%$ ethanol for amaranth and quinoa. In contrast, the free antioxidant activities from water were lower than those from and $50 \%$ ethanol for teff and buckwheat. Therefore, the conclusion of solvent selection for free antioxidant activities regarding water and $50 \%$ ethanol are inclusive. 
Table 3. Free bound and total antioxidant activities of ancient grain products in aqueous extracts using water $50 \%$ ethanol and $100 \%$ ethanol.

\begin{tabular}{ccccccc}
\hline Product & Ethanol (\%) & Free $\boldsymbol{\mu \mathbf { m o l } / \mathbf { g }}$ & \% of total & Bound $\boldsymbol{\mu m o l} / \mathbf{g}$ & \% of total & Total $\boldsymbol{\mu m o l} / \mathbf{g}$ \\
\hline Amaranth & 0 & $0.97 \pm 0.04 \mathrm{i}$ & 8.90 & $9.92 \pm 0.04 \mathrm{~d}$ & 91.01 & $10.90 \pm 0.04 \mathrm{~h}$ \\
Amaranth & 50 & $0.58 \pm 0.02 \mathrm{j}$ & 5.54 & $9.88 \pm 0.02 \mathrm{~d}$ & 94.46 & $10.46 \pm 0.04 \mathrm{j}$ \\
Amaranth & 100 & $0.13 \pm 0.02 \mathrm{l}$ & 1.30 & $9.90 \pm 0.02 \mathrm{~d}$ & 98.70 & $10.03 \pm 0.03 \mathrm{k}$ \\
Quinoa & 0 & $5.08 \pm 0.02 \mathrm{a}$ & 33.55 & $10.06 \pm 0.02 \mathrm{c}$ & 66.45 & $15.14 \pm 0.06 \mathrm{~b}$ \\
Quinoa & 50 & $3.94 \pm 0.03 \mathrm{f}$ & 29.01 & $9.63 \pm 0.03 \mathrm{e}$ & 70.91 & $13.58 \pm 0.10 \mathrm{e}$ \\
Quinoa & 100 & $0.49 \pm 0.05 \mathrm{k}$ & 4.63 & $10.09 \pm 0.05 \mathrm{c}$ & 95.37 & $10.58 \pm 0.10 \mathrm{i}$ \\
Teff & 0 & $4.21 \pm 0.03 \mathrm{e}$ & 29.03 & $10.28 \pm 0.03 \mathrm{~b}$ & 70.90 & $14.50 \pm 0.03 \mathrm{~d}$ \\
Teff & 50 & $4.88 \pm 0.00 \mathrm{c}$ & 32.13 & $10.31 \pm 0.00 \mathrm{~b}$ & 67.87 & $15.19 \pm 0.09 \mathrm{~b}$ \\
Teff & 100 & $2.37 \pm 0.02 \mathrm{~h}$ & 18.53 & $10.42 \pm 0.02 \mathrm{a}$ & 81.47 & $12.79 \pm 0.02 \mathrm{~g}$ \\
Buckwheat & 0 & $4.50 \pm 0.03 \mathrm{~d}$ & 30.32 & $10.25 \pm 0.03 \mathrm{ab}$ & 69.07 & $14.84 \pm 0.03 \mathrm{c}$ \\
Buckwheat & 50 & $5.02 \pm 0.01 \mathrm{~b}$ & 32.53 & $10.40 \pm 0.01 \mathrm{a}$ & 67.40 & $15.43 \pm 0.02 \mathrm{a}$ \\
Buckwheat & 100 & $2.60 \pm 0.00 \mathrm{~g}$ & 20.09 & $10.33 \pm 0.00 \mathrm{ab}$ & 79.83 & $12.94 \pm 0.02 \mathrm{f}$ \\
\hline
\end{tabular}

The different letters indicated the significances between treatments in column $(p<0.05)$.

\section{Conclusion}

Amaranth, quinoa, teff and buckwheat all have special nutrients. Higher water holding capacities were found for the ancient grain flours than wheat flour. Buckwheat flour had the highest free, bound and total phenolic contents among the four products. In general, the bound phenolic contents and antioxidant properties were higher than the free phenolic contents and antioxidant activates regardless of the ethanol concentrations. The free phenolic compounds and antioxidant activities for all four products were significantly higher in extracts using water and $50 \%$ ethanol than $100 \%$ ethanol. In contrast, more bound phenolics were in $100 \%$ ethanol extracts than water and 50\% ethanol extracts. Our study suggested that the total phenolic contents and antioxidant activities of grains could be underestimated in the literature without considering the bound phenolic compounds. These ancient grains have nutritional value, antioxidants, and texture qualities suitable for functional food applications.

\section{References}

[1] Mayo Clinic (2014) Gluten-Free Diet.

http://www.mayoclinic.org/healthy-living/nutrition-and-healthy-eating/in-depth/gluten-free-diet/art-20048530

[2] de Macvean, A.L. and Pöll, E. (1997) Chapter 8: Ethnobotany. Tropical Tree Seed Manual, USDA Forest Service.

[3] USDA Nutrient Database (2014) http://ndb.nal.usda.gov/ndb/search/list

[4] Myers, L.R. and Putnam, H.D. (1988) Growing Grain Amaranth as a Specialty Crop. In Crop Systems. University of Minnesota. FS-03458-GO.

[5] Martirosyan, D.M., Miroshnichenko, L.A., Kulakova, S.N., Pogojeva, A.V. and Zoloedov, V.I. (2007) Amaranth Oil Application for Coronary Heart Disease and Hypertension. Lipids Health Disease, 6, 1. http://dx.doi.org/10.1186/1476-511X-6-1

[6] Vaughn, J.G. and Geissler, C.A. (2009) The New Oxford Book of Food Plants. 2nd Edition, Oxford University Press, Oxford.

[7] Hirose, Y., Fujita, T., Ishii, T. and Ueno, N. (2010) Antioxidative Properties and Flavonoid Composition of Chenopodium quinoa Seeds Cultivated in Japan. Food Chemistry, 119, 1300-1306. http://dx.doi.org/10.1016/j.foodchem.2009.09.008

[8] James, L.E.A. (2009) Chapter 1: Quinoa (Chenopodium quinoa Willd.): Composition, Chemistry, Nutritional, and Functional Properties. Advances in Food and Nutrition Research, 58, 1-31. http://dx.doi.org/10.1016/S1043-4526(09)58001-1 
[9] Taha, S.E., Shahira, M.E. and Amani, A.S. (2012) Chemical and Biological Study of the Seeds of Eragrostis tef (Zucc.) Trotter. Natural Product Research: Formerly Natural Product Letters, 26, 619-629. http://dx.doi.org/10.1080/14786419.2010.538924

[10] Wijngaard, H.H. and Arendt, E.K. (2006) Buckwheat. Cereal Chemistry, 8, 391-401. http://dx.doi.org/10.1094/CC-83-0391

[11] Holasova, M., Fiedlerova, V., Smrcinova, H., Orsak, M., Lachman, J. and Vavreinova, S. (2002) Buckwheat-The Source of Antioxidant Activity in Functional Foods. Food Research International, 35, 207-211. http://dx.doi.org/10.1016/S0963-9969(01)00185-5

[12] Zdunczyk, Z., Flis, M., Zielinski, H., Wroblewska, M., Antoszkiewicz, Z. and Juskiewicz, J. (2006) In Vitro Antioxidant Activities of Barley, Husked Oat, Naked Oat, Triticale, and Buckwheat Wastes and Their Influence on the Growth and Biomarkers of Antioxidant Status in Rats. Journal of Agricultural and Food Chemistry, 54, 4168-4175. http://dx.doi.org/10.1021/jf060224m

[13] Morishita, T., Yamaguchi, H. and Degi, K. (2007) The Contribution of Polyphenols to Antioxidative Activity in Common Buckwheat and Tartary Buckwheat Grain. Plant Production Science, 10, 99-104. http://dx.doi.org/10.1626/pps.10.99

[14] Ayo, J.A. (2001) The Effect of Amaranth Grain Flour on the Quality of Bread. International Journal of Food Properties, 4, 341-351. http://dx.doi.org/10.1081/JFP-100105198

[15] Schoenlechner, R., Wendner, M., Siebenhandl-Ehn, S. and Berghofer, E. (2010) Pseudocereals as Alternative Sources for High Folate Content in Staple Foods. Journal of Cereal Science, 52, 475-479. http://dx.doi.org/10.1016/j.jcs.2010.08.001

[16] Costantini, L., Lukšič, L., Molinari, R., Kreft, I., Bonafaccia, G., Manzi, L. and Merendino, N. (2014) Development of Gluten-Free Bread Using Tartary Buckwheat and Chia Flour Rich in Flavonoids and Omega-3 Fatty Acids as Ingredients. Food Chemistry, 165, 232-240. http://dx.doi.org/10.1016/j.foodchem.2014.05.095

[17] Collar, C., Jiménez, T., Conte, P. and Fadda, C. (2014) Impact of Ancient Cereals, Pseudocereals and Legumes on Starch Hydrolysis and Antiradical Activity of Technologically Viable Blended Breads. Carbohydrate Polymers, 113, 149-158. http://dx.doi.org/10.1016/j.carbpol.2014.07.020

[18] Kaliora, A.C. and Dedoussis, G.V. (2007) Natural Antioxidant Compounds in Risk Factors for CVD. Pharmacological Research, 56, 99-109. http://dx.doi.org/10.1016/j.phrs.2007.04.018

[19] Serafini, M., Bellocco, R., Wolk, A. and Ekstrom, A.M. (2002) Total Antioxidant Potential of Fruit and Vegetables and Risk of Gastric Cancer. Gastroenterology, 123, 985-991. http://dx.doi.org/10.1053/gast.2002.35957

[20] Frusciante, L., Carli, P., Ercolano, M.R., Pernice, R., Di Matteo, A., Fogliano, V. and Pellegrini, N. (2007) Antioxidant Nutritional Quality of Tomato. Molecular Nutrition and Food Research, 51, 609-617. http://dx.doi.org/10.1002/mnfr.200600158

[21] Serpen, A., Gökmen, V., Pellegrini, N. and Fogliano, V. (2008) Direct Measurement of the Total Antioxidant Capacity of Cereal Products. Journal of Cereal Science, 48, 816-820. http://dx.doi.org/10.1016/j.jcs.2008.06.002

[22] Ade-Omowaye, B.I.O., Taiwo, K.A., Eshtiaghi, N.M., Angersbach, A. and Knorr, D. (2003) Comparative Evaluation of the Effects of Pulsed Electric Field and Freezing on Cell Membrane Permeabilisation and Mass Transfer during Dehydration of Red Bell Peppers. Innovative Food Science \& Emerging Technologies, 4, 177-188. http://dx.doi.org/10.1016/S1466-8564(03)00020-1

[23] Adom, K.K. and Liu, R.H. (2002) Antioxidant Activity of Grains. Journal of Agricultural and Food Chemistry, 50, 6182-6187. http://dx.doi.org/10.1021/jf0205099

[24] Waterhouse, A.L. (2001) Determination of Total Phenolics. In: Wrolstad, R.E., Ed., Current Protocols in Food Analytical Chemistry, John Wiley \& Sons, New York, I1.1.1-I1.1.8.

[25] Yu, L. and Zhou, K. (2004) Antioxidant Properties of Oat Bran Extracts from 'Platte' Wheat Grown at Different Locations. Food Chemistry, 90, 311-316. http://dx.doi.org/10.1016/j.foodchem.2004.04.007

[26] Şensoy, I., Rosén, R.T., Ho, C.T. and Karwe, M.V. (2006) Effect of Processing on Buckwheat Phenolics and Antioxidant Activity. Food Chemistry, 99, 388-393. http://dx.doi.org/10.1016/j.foodchem.2005.08.007

[27] SAS Institute Inc. (1999) The SAS ${ }^{\circledR}$ System for Windows ${ }^{\circledR}$, Version 8e. Cary.

[28] University of Maryland Medical Center (2013) http://umm.edu/health/medical/altmed/supplement/vitamin-k\#ixzz33t70aIeT

[29] Guha, M., Zakiuddin Ali, S. and Bhattacharya, S. (1998) Effect of Barrel Temperature and Screw Speed on Rapid Viscoanalyser Pasting Behaviour of Rice Extrudate. International Journal of Food Science and Technology, 33, 259266. http://dx.doi.org/10.1046/j.1365-2621.1998.00189.x

[30] Clifford, M.N. (1999) Chlorogenic Acids and Other Cinnamates-Nature, Occurrence and Dietary Burden. Journal of 
the Science of Food and Agriculture, 79, 362-372.

http://dx.doi.org/10.1002/(SICI)1097-0010(19990301)79:3<362::AID-JSFA256>3.0.CO;2-D

[31] Herrmann, K. and Nagel, C.W. (1989) Occurrence and Content of Hydroxycinnamic and Hydroxybenzoic Acid Compounds in Foods. Critical Reviews in Food Science and Nutrition, 28, 315-347.

http://dx.doi.org/10.1080/10408398909527504 